\title{
Recharging Family Medicine: A Perspective from the Keystone IV Conference
}

\author{
Rosemary A. Stevens, PhD, MPH
}

A historic perspective of family medicine's development, the work of Gayle Stephens, and prior Keystone conferences constitute an important backdrop for the fourth Keystone Conference. Decisions made in the past constrain what can be done now, but they may also offer opportunities for family medicine. A major challenge for Keystone IV was to discern what is a constraint and what is an opportunity-in particular when it comes to the role of the personal physician. This article provides reflections based on decades of observation and study and confirms that knowing something and doing something are not the same. (J Am Board Fam Med 2016;29:S15-S18.)

Guest editors' note: This paper was commissioned to help prepare attendees for participation in the G. Gayle Stephens Keystone IV Conference. It reveals the historical context provided by Dr. Rosemary Stevens at the conference. It reprises her report from the third Keystone Conference in October 2000 and calls out anticipated and unanticipated changes that did and did not occur in the interval.

Keywords: Doctoring, Family Medicine, Family Physician, Health Care Delivery, Personal Physician, Population Health, Primary Care, Professionalism, Social Justice

It was my honor and pleasure at Keystone IV to recognize the extraordinary role of Gayle Stephens in developing the field of family medicine. He left a rich, deeply human, and challenging legacy behind him. But over the years, the framework of medicine has changed. As a historian of the medical profession and a long-time champion of family medicine, I have served as a witness to changes in US health care-like others from the oldest generation, who can look back 40 or 50 years. This conference offers an invaluable image of the state of family medicine in the United States in 2015. My remarks are designed to put them in a longer per-

This article was externally peer reviewed.

Submitted 14 December 2015; revised 9 March 2016; accepted 17 March 2016.

From the Department of Psychiatry, Well Cornell Medical College, New York, NY.

Funding: none.

Conflict of interest: none declared.

Corresponding author: Rosemary A. Stevens, PhD, MPH, Department of Psychiatry, Well Cornell Medical College, Box 171, 1300 York Ave, New York, NY 10021 (E-mail: ras2023@med.cornell.edu). spective in terms both of mission and workable ideas. Decisions made in times past constrain what can be done now, but change offers opportunities. A major job for Keystone IV is teasing out which is which.

\section{Invention: 1960s to $1980 \mathrm{~s}$}

The family medicine movement of the 1960s was energized by the belief that the obvious value of family medicine (and the willingness to train its practitioners) would stimulate a revolution by patients, within medicine, and in government that would lead to broader clinical and educational reforms based on a new commitment to generalism. In short, family medicine was a moral necessity, and the time for change had come. Gayle Stephens, the major philosopher of the movement, spoke of a "counterculture" to the dislocations wrought by science. Looking back at the time of Keystone II in 1988, he wrote, "There is a sense of having participated in something that is a great deal bigger than oneself and one's ideas." 
This sense of commitment carries many present-day family physicians through the irritations and irrationalities of practice demands in our present. As we all know, however, the 1960s revolution was not achieved as hoped; this was despite the fact that, even then, it had long been known that sickness is related to social, economic, and environmental factors; that the aging of the population brings an increasing need for the "caring" and connecting parts of medicine; and that specialty care must be coordinated. Several significant reports in the 1960s called for initiatives in primary care, specifically for the patient-centered personal physician that the family medicine movement expected to provide. However, knowing something and doing something are 2 very different things. American medical schools in the 1960s and later were oriented toward hospital specialty practice and research. Private health insurance was designed to cover in-hospital services and high-cost procedures over comprehensive care. Medicare and Medicaid followed this model. Free choice of specialist by individual patients (a choice not advised by a personal physician) was assumed. Without a huge public movement demanding well-organized services, and without a substantial, continuing funding stream, family medicine was difficult to sustain. In the 1970s and 1980s, market approaches to health care reform brought the language of a medical care "industry" to the fore, with doctors as providers and patients as consumers. Gayle Stephens pressed on. "Our naïve romance with reform in medical education and practice has been blunted by experience," he told Keystone II in 1988, "but the spirit of reform is alive in this group." 2

Is the spirit of reform enough? Then as now, the answer is, sadly, no. Involvement in the practical worlds of politics and economics is essential if idealism is to be expressed in action. This is not to say that every dedicated physician has to be a mover and shaker. Rather, as the field of health care changes, family medicine must be at the table and ready with a practical, creative response to questions. Where, for example, are there opportunities for a family medicine-based revolution in federal Medicare and state-based Medicaid programs that seek to counter dangers of overtreatment, unnecessary treatment, and lack of communication?

Gayle Stephens recognized the importance of language in motivating constructive change. "Counterculture" is a case in point. There has been no word or phrase as powerful as that since. In the late 1980s and into the 1990s, insurance companies jumped on the bandwagon of "managed care," by which a physician would act as a so-called gatekeeper to more expensive specialties. In a different environment leaders in family medicine might have joined forces with major insurers to advance better care for patients-and might have chosen a more appealing slogan. Gatekeeping suggested (and was) "rationing," an incendiary word politically, and physicians did not want to be the tools of insurance companies. Meanwhile health care costs continued to rise while the system remained fragmented and, from the patient's point of view, distressingly uncoordinated.

\section{Keystone III}

By the year 2000, when Keystone III was held, corporatization of health care had taken hold, but by then family medicine had taken a new tack by becoming a specialty within the "House of Medicine" and thus part of the dominant medical culture. The American Board of Family Medicine was the 20th member of the American Board of Medical Specialties. Its symbol was hopeful: "Phoenix rising from the flames." The board has been an impressive professional organization from the start, with state-of-the-art examinations and computerassisted lifelong learning modules, recertification requirements, university departments in many schools, and approved residency positions-but still without a generally defined practice role within the larger health care system. Subspecialty certificates for family medicine followed: geriatric medicine and sports medicine in the 1980s and adolescent medicine in 2000, then hospital and palliative medicine, sleep medicine, and pain medicine. Meanwhile new competition for the role of primary care came from general internal medicine, the combination of internal medicine and pediatrics, and the rise and success of the nurse practitioner movement.

The organizers of Keystone III noted "great upheaval" throughout the health care system and within family medicine. ${ }^{3}$ An article on "bad deals" and "missed opportunities" recommended, among other things, dropping the counterculture idea because it was antagonistic to other medical specialties; designing new clinical practice models based 
on the "best of technology, innovation and management"; and developing a research and development agenda. ${ }^{4}$ In my article for Keystone III I observed that family medicine needed more status and visibility in major research medical schools and that leaders in the field had not explained or exploited the idea of "family" in its title and had not yet defined its special interests in research and technology—a fundamental defining factor for other fields of medicine. Smooth-running computerized information systems (when they work) continue to be a potential centering vehicle for family medicine, smoothing daily life in the practice and providing invaluable research data. ${ }^{5}$

It was as clear in 2000, as it is now, that education and training alone do not provide the necessary work opportunities or a population of patients for family medicine (or any other field) to thrive. There has to be a structure-at the very least, financial support of family medicine practices via health insurance or other means, patient self-referral, and an equitable 2-way referral system with physicians and other health professionals in different fields. The medical profession has not completely absorbed the message that education alone does not lead to system reform; rather, the system shapes what practitioners and patients do. One of the fallacies behind current debates of whether there is a doctor shortage has been an emphasis on the number of individuals trained rather than a restructuring of roles and practices for the benefit of patients. ${ }^{6}$

\section{Where Are We Now?}

The US health care system is in many ways absurd. We all know the descriptors: wasteful, unfair, overspecialized, neglecting health and disease prevention in favor of disease, unwieldy, insufficiently patient-friendly, cumbersome information technology, too little time for talk sessions, endless insurance forms, poor quality ratings compared with other leading nations. The list goes on. Against such odds, we might say that family medicine has done well. One of the most exciting issues for Keystone IV is to describe the various ways in which successful family practitioners feel pride and satisfaction in their work, provide excellent patient care, and organize their practices today. Yet the potential rewards of a career in family medicine are not sufficiently visible in the specialty choices made by medical students. Less than $9 \%$ of US medical graduates with an MD degree entered family medicine residencies in 2013. Arguably, the number of trainees in the pipeline is too small to affect the culture of medical education and training as a whole. But that did not deter Gayle Stevens in the 1960s. Greater efforts are needed in terms of communication.

Huge changes in the drivers of medicine have occurred over the past 15 years: universal digital technology, skilled nurse practitioners and physician assistants, the Affordable Care Act, changes in the organization of Medicaid services in different states, substantial expertise within major business corporations in the organization of and insurance for health care, family practice residencies in community settings rather than hospitals, pressures for behavioral health as part of primary care, an aging population that would like to be kept well until their dying day, concern about unnecessary (and dangerous) treatment and the problem of overtreatment, refocus on health rather than disease, hospitalists taking over inpatient care, and the rise of hospital-based health care systems. Whether these and other changes will serve to reinvigorate family medicine at the national, state, and local levels will require the enthusiasm, moral force, and leadership Stephens and others brought to the field a half-century ago.

The motivating word counterculture might even be brought back, faute de mieux, for as yet no other single word has captured the importance of a family medicine movement in our present. Instead there are multiple words, including the "triple aim" of better health, better health care, and lower costs for patients. Other concepts include job satisfaction, skills, outlook, moral philosophy, well-organized practices, attention to patients' needs, and lifestyle. And questions abound. How far should the meaning of "family" in family medicine be enlarged to embrace concepts of community, public service, and reciprocity across generations? Who are now the best allies, inside and outside of the health professions, to work with locally and nationally? This promises to be an exciting time. It is also a time when clarity of purpose is essential.

Where would family medicine like to go-and what does it need to get there?

Keystone IV offers a unique opportunity for today's clinical entrepreneurs not only to share per- 
sonal experiences but also to explicate the meaning (or meanings) of the mission in 2015 and to brainstorm ideas about the future, including what promises a personal physician will make-and keep.

\section{References}

1. Stephens GG. Family medicine as counterculture. Fam Med 1989;21:103-8.

2. Unpublished Memorandum from G. Gayle Stephens, September 24, 1988. STFM Foundation.

3. Green LA, Graham R, Stephens GG, Frey JK. A preface concerning Keystone IIII. Fam Med 2001;33:230.
4. Magill MK, Kane WJ. What opportunities have we missed, and what bad deals have we made? Fam Med 1961;33:268-72.

5. Stevens RA. The Americanization of family practice: contradictions, challenges and changes, 1969-2000. Fam Med 2001;33:232-41.

6. Bernstein L. U.S. faces 90,000 doctor shortage by 2025, medical school association warns. Washington Post, March 3, 2015. Available from: https:// www.washingtonpost.com/news/to-your-health/wp/ 2015/03/03/u-s-faces-90000-doctor-shortage-by2025-medical-school-association-warns/. Accessed June 23, 2016. 